\title{
Pseudomicetoma felino causado por Microsporum canis. Descripción de un caso clínico y su tratamiento
}

\author{
Tonelli, E.A.; Duchene, A.; Loiza, M.; Scarpa, M.A.; Reynes, L. \\ Hospital Escuela de Medicina Veterinaria, Fac.Cs.Vet.Univ.Bs.As. Avenida San Martín 4453, \\ Ciudad de Buenos Aires (1427), Argentina. Teléfono (011) 4524-8496. \\ E-mail: tonellieduardoalberto@gmail.com
}

\begin{abstract}
Resumen
Tonelli, E.A.; Duchene, A.; Loiza, M.; Scarpa, M.A.; Reynes, L.: Pseudomicetoma felino causado por Microsporum canis. Descripción de un caso clínico y su tratamiento. Rev. vet. 27: 2, 141-143, 2016. En la presente comunicación se describe un caso clínico de dermatofitosis en un gato persa, producida por Microsporum canis, con manifestaciones cutáneas de pseudomicetoma (granuloma de Majocchi). Se detallan los diagnósticos clínico e histopatológico, así como el tratamiento instaurado.
\end{abstract}

Palabras clave: felino, dermatofitosis, pseudomicetoma, Microsporum canis, granuloma de Majocchi.

\begin{abstract}
Tonelli, E.A.; Duchene, A.; Loiza, M.; Scarpa, M.A.; Reynes, L.: Feline pseudomicetoma caused by Microsporum canis. Description of a clinical case and their treatment. Rev. vet. 27: 2, 141-143, 2016. In this report, a clinical case of dermatophytoses in a Persian cat produced by Microsporum canis, was described. Clinical signs of seudomycetoma (Majocchi's granuloma), as well as histopathological lesions and established treatment, were detailed.
\end{abstract}

Key words: feline, dermatophitoses, pseudomycetoma, Microsporum canis, Majocchi's granuloma.

\section{INTRODUCCIÓN}

Las dermatofitosis (tiñas) que más comúnmente afectan a los felinos son las producidas por Microsporum sp. y Trichophyton sp., especialmente Microsporum canis ${ }^{2,3,5}$. Se transmiten por contacto directo con pelos infectados y escamas o elementos fúngicos presentes sobre el animal o en el ambiente y por fómites (peines, cepillos, camas) ${ }^{2}$. La fuente de infección más común para M. canis es usualmente un gato infectado.

Trichophyton $s p$. es adquirido usualmente por exposición directa o indirecta en los lugares de hospedaje donde hay roedores. Los dermatofitos habitan los tejidos queratinizados como el estrato córneo epidérmico, pelos y uñas. Las artrosporas pueden mantenerse infectivas hasta 18 meses, incluso en el piso del consultorio ${ }^{8}$. Una vez resuelto el cuadro clínico, los animales pueden permanecer como portadores asintomáticos ${ }^{7}$.

Cuando un animal es expuesto a un dermatofito, puede establecerse una infección ${ }^{3}$. La defensa natural del animal incluye sequedad y descamación del estrato córneo, así como secreción de las glándulas sebáceas y apócrinas, las cuales poseen propiedades fungistáticas. Las hifas invaden el estrato córneo y el pelo

Recibido: 3 mayo 2016 / Aceptado: 14 junio 2016 hasta el bulbo piloso, llegando al margen de Adamson. El hongo siempre se desarrolla sobre pelos en fase de crecimiento (anagenia), pero el desarrollo micótico puede detenerse cuando el pelo entra en fase de reposo (telogenia). En modelos experimentales, el período de incubación entre inoculación y desarrollo de lesiones clínicas fue de 7 a 14 días ${ }^{5}$.

La inflamación cutánea que generan los dermatofitos es debida a las toxinas producidas en el estrato córneo, las cuales generan una dermatitis de contacto. La habilidad del hospedador para poner en marcha una respuesta inflamatoria asume un rol crítico en la determinación del tipo de lesión a producirse ${ }^{5}$.

M. canis posee numerosas propiedades enzimáticas, que varían de acuerdo a la cepa del hongo. Su queratinasa es una proteinasa (quimotripsina) que se asocia a inflamación y prurito ${ }^{10}$. No existe correlación entre los anticuerpos circulantes y la protección contra la infección. Al re-exponerse a la noxa, los felinos recuperados de una infección por $M$. canis pueden no padecer síntomas o bien generar lesiones inflamatorias mucho más leves. Se afirma que la defensa más importante proviene del ámbito de la inmunidad celular ${ }^{6}$.

La dermatofitosis felina se presenta comúnmente como una o más áreas de alopecia anular o irregular, con o sin escamas. En dichas áreas los pelos están ro- 
tos y ralos. La hiperqueratosis folicular puede dar como resultado una abertura exagerada del folículo y la formación de comedones. La alopecia puede ser severa y diseminada, con escasa evidencia de inflamación. El pseudomicetoma dermatofítico ha sido reportado solo en gatos persas, caracterizándose por uno o más nódulos subcutáneos que a menudo están ulcerados y drenan ${ }^{1,4}$.

Los nódulos se observan más comúnmente en la zona dorsal del tronco y en la base de la cola. A veces los gatos afectados pueden exhibir simultáneamente lesiones dermatofíticas superficiales en otras partes del cuerpo. Se especula que la aparición del pseudomicetoma estaría asociada a una alteración del sistema inmune, que se produciría cuando una porción de epidermis -incluyendo pelos- se desprende tras la generación de una respuesta a cuerpo extraño generada en la dermis profunda. El pelo será reabsorbido pero los elementos micóticos permanecen por largos periodos. El hongo no prolifera en la dermis pero es secuestrado en forma pasiva y persiste durante un periodo prolongado de tiempo (granuloma de Majocchi).

\section{MATERIAL Y MÉTODOS}

Se presentó a consulta un felino persa, de dos años de edad, apreciándose dos lesiones nodulares en tronco y base de la cola, de 3 y $5 \mathrm{~cm}$ de diámetro respectivamente (Foto 1), las cuales estaban ulceradas y drenaban. Una de ellas presentó un nódulo ulcerado de gran tamaño y otra lesión más pequeña (Foto 2), con abundante

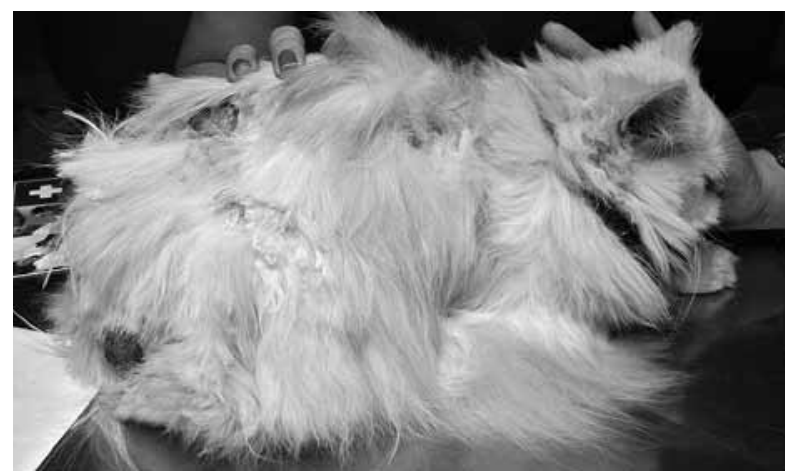

Foto 1. Severas lesiones ulceradas en región lumbosacra y perianal.

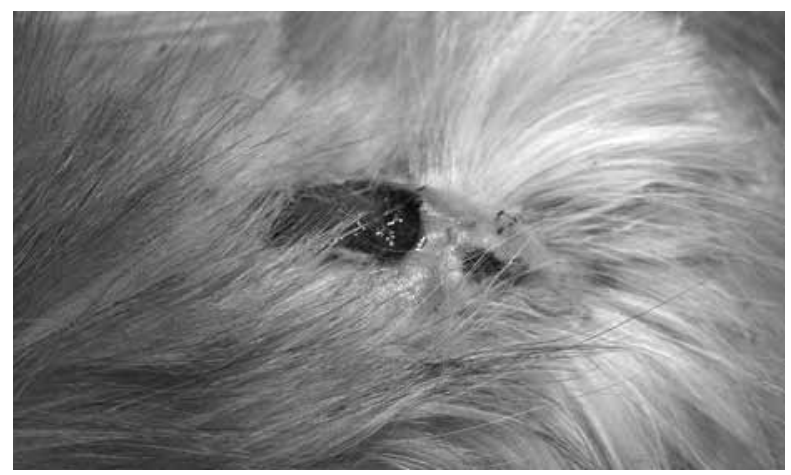

Foto 2. Detalle del nódulo ulcerado correspondiente al pseudomicetoma.

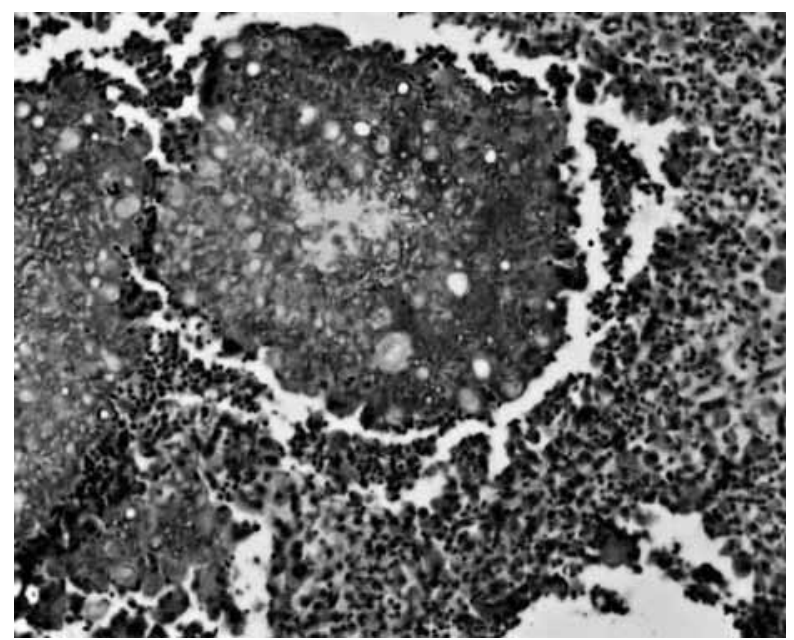

Foto 3. Corte histopatológico del granuloma de Majocchi mostrando gran cantidad de neutrófilos y microsporas (HyE, 40x).

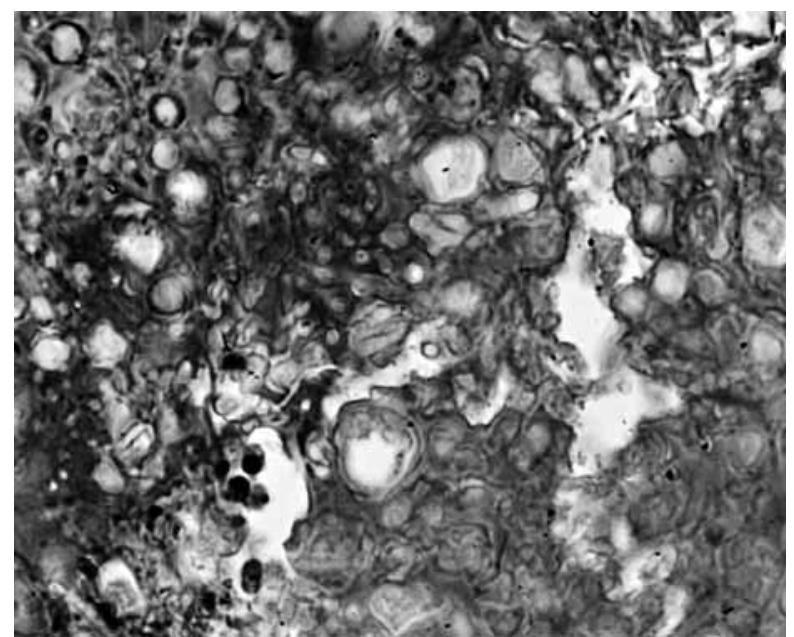

Foto 4. Corte histológico donde se observan las hifas características de Microsporum canis (HyE, 40x).

drenaje. Los nódulos eran firmes y se desplazaban sobre el tejido subyacente.

El propietario relató que el gato estaba siendo medicado empíricamente con amoxicilina/ácido clavulánico desde hacía 20 días ( $22 \mathrm{mg} / \mathrm{kg} \mathrm{c} / 12$ h), sin mejoría significativa. Teniendo en cuenta el aspecto de las lesiones y la raza del felino, el diagnóstico diferencial incluyó entidades como dermatofitosis en forma de pseudomicetoma, granuloma a cuerpo extraño, paniculitis estéril y algún tipo de neoplasia, muy improbable debido a la joven edad del paciente.

Se tomó impronta de la lesión, algunos pelos para observación directa y cultivo, así como una muestra para histopatología.

\section{RESULTADOS}

La impronta coloreada con "tinción 15 " reveló numerosas bacterias y granulocitos neutrófilos no tóxicos. En la observación de pelos tratados con "azul de algodón" (azul de lactofenol) se hicieron evidentes nume- 
rosos conidios formando un patrón en mosaico sobre la superficie del pelo, fuera del tallo piloso (invasión ectótrica). También se visualizaron hifas penetrando dentro del tallo piloso.

La histopatología (tinción PAS, ácido periódico de Schiff) mostró un estrato córneo con hifas tabicadas y conidios esféricos y ovales. Además, se reveló presencia de foliculitis, perifoliculitis, forunculosis y dermatitis perivascular (espongiosa) con hiperqueratosis paraqueratósica de epidermis y folículos pilosos, dermatitis pustulosa intraepidérmica (espongiosis), dermatitis nodular granulomatosa dentro de la dermis (granuloma micótico o granuloma de Majocchi), con abundante presencia de hifas grandes, anchas, hialinas y septadas (fotos 3 y 4 ).

El propietario recibió instrucciones de afeitar al gato, someterlo a baños semanales con champú de ketoconazol y clorhexidina al $2 \%$ y efectuar tratamiento sistémico con cefalexina $22 \mathrm{mg} / \mathrm{kg}$ cada 12 horas e itraconazol $10 \mathrm{mg} / \mathrm{kg}$ cada $12 \mathrm{~h}$. No se efectuó escisión quirúrgica de las lesiones debido al gran tamaño de las mismas, pero no se descartó como tratamiento futuro para el caso en que pudiera reducirse el tamaño de los granulomas.

Habiendo transcurrido 30 días del comienzo del tratamiento, el propietario comunicó telefónicamente la resolución casi completa de las lesiones, aguardando una próxima consulta para poder evaluarlo.

\section{DISCUSIÓN}

Si bien las dermatofitosis son frecuentes en la práctica diaria, la presentación de un pseudomicetoma felino siempre es motivo de curiosidad y atención especial, no solo por infrecuente ${ }^{1,2,4}$, sino porque el tratamiento suele ser bastante más largo y complicado que el de una dermatofitosis común ${ }^{5}$.

Habida cuenta de la toxicidad y escasa respuesta observada con ketoconazol ${ }^{9}$, actualmente se preferencian los tratamientos con drogas azólicas como itraconazol o terbinafina. En caso de ser factible también está indicada la cirugía de las lesiones. En cuanto a la duración del tratamiento, se aconseja continuarlo 60 días más luego de desaparecidos los signos clínicos. Es importante tener en cuenta la raza persa y la edad de aparición, dos datos muy sugestivos de hallazgo muy frecuente en esta patología.

En conclusión, se efectúa una actualización sobre la etiopatogenia y los aspectos clínicos de las dermatofitosis del gato, describiéndose un infrecuente caso de pseudomicetoma felino.

Agradecimiento. A la Dra. Mariángeles Gayoso, pasante del Servicio de Dermatología del Hospital Escuela, por su inestimable colaboración.

\section{REFERENCIAS}

1. Bergman RL, Medleau L, Hnilica K. 2002. Dermatophyte granulomas caused by Trichophyton mentagrophytes in a dog. Vet Dermatol $13: 49-52$.

2. DeBoer DJ, Moriello KA. 1995. Clinical update on feline dermatophytosis. Part I. Compend Contin Educ 17: 1197.

3. De Jaham C, Paradis M.1997. La dermatophytose féline: Étiopathogénie, aspects cliniques et príncipes diagnostiques. Méd Vét Québec 27: 141-155.

4. Flaig K, Kresken JG, Weber A, Pfleghaar S, Saers KJ. 1999. Dermatophyte pseudomycetoma in a cat caused by Microsporum canis. Praktische Tierarzt 80: 398-401.

5. Foil CS. 1993. Dermatophytosis. In: Current Veterinary Dermatology (Griffin CE ed.), Ed. Mosby, St. Louis (USA), p. 22-25.

6. Jones HE. 1993. Immune response and host resistance of humans to dermatophyte infection. J Am Acad Dermatol 28: 12-18.

7. Lewis DT, Foil CS, Hopgood G. 1991. Epidemiology and clinical features of dermatophytosis in dogs and cats at Louisiana State University: 1981-1990. Vet Dermatol 2: 53-58.

8. Mancianti F, Papini R. 1996. Isolation of keratinophilic fungi from the floors of private veterinary clinics in Italy. Vet Res Commun 20: 161-168.

9. Medleau L, Chalmers SA. 1992. Ketoconazole for treatment of dermatophytosis in cats. J Am Vet Med Assoc 200: 77-78.

10. Mignon B, Boruta F, Descamps F. 2000. Microsporum canis virulence factors and immunogens: first purification and characterization of a $43.5 \mathrm{kDa}$ keratinolytic protease (abstract). Vet Dermatol 11 (suppl 1): 39. 
